\title{
TORRES FUNERARIAS PREHISPÁNICAS DE LOS ANDES CENTRO-SUR: MUERTE, OCUPACIÓN DEL ESPACIO Y ORGANIZACIÓN SOCIAL. ESTUDIO COMPARATIVO: COPORAQUE, CAÑÓN DEL COLCA (PERÚ), CHAPIQUIÑA, PRECORDILLERA DE ARICA (CHILE)*
}

\author{
PREHISPANIC FUNERARY TOWERS OF THE SOUTH-CENTRAL ANDES: \\ DEATH, SPACE OCUPATION AND SOCIAL ORGANIZATION. COMPARATIVE \\ STUDY: COPORAQUE, CAÑON DEL COLCA (PERU), CHAPIQUIÑA, \\ PRECORDILLERA OF ARICA (CHILE)
}

Frédéric Duchesne $e^{1}$ y Juan Chacama ${ }^{2}$

\begin{abstract}
Las costumbres funerarias del período Intermedio Tardío se caracterizan por la aparición de sepulturas sobreelevadas cuyas funciones -fuera de aquella, obvia, de conservar al cadáver- se encuentran aún poco conocidas. Este estudio comparativo aspira a determinar si aquella "costumbre" común a todos los Andes del Centro-Sur de depositar el cadáver en un sepulcro de fácil acceso, visible y abierto traduce una uniformidad de las prácticas funerarias y de las actitudes frente a la muerte dentro de las sociedades andinas. Palabras claves: muerte, chullpa, período Intermedio Tardío, valle del Colca, Precordillera de Arica.
\end{abstract}

This comparative study intends to determine whether the common practice to all south-central Andes of burying bodies in easily accessible, visible, and open tombs originated from standardized funerary practices and attitudes toward death among Andean societies.

Key words: Death, chullpa, Late Intermediate Period, Colca valley, Precordillera of Arica.

\begin{abstract}
Show me the manner in which a nation or a community cares for its dead. I will measure exactly the sympathies of its people, their respect for the laws of the land, and their loyalty to high ideals. William Ewart Gladstone (1809-1898).
\end{abstract}

Durante el período Intermedio Tardío (ca. 1.0001.400 d.C.) se generaliza en los Andes del Centro-Sur un nuevo tipo de sepulturas cuyas principales características son las de ser sobreelevadas y "abiertas", o sea con un vano de acceso. Ya en el siglo XVI esas casas funerarias, llamadas comúnmente chullpas en la documentación colonial, llamaron mucho la atención de los primeros europeos que arribaron a los Andes ${ }^{1}$; fueron objeto de curiosidad de los viajeros del siglo $\mathrm{XIX}^{2}$ y suscitado un número creciente de estudios a lo largo del siglo $\mathrm{XX}^{3}$.
Esta costumbre funeraria está difundida en una amplia área y no se puede delimitar a una zona cultural "chullpa" que sería el hecho de un pueblo específico o de una etnia. Tanto las crónicas ${ }^{4}$ como los últimos avances arqueológicos (Sobczyk 2001) dejan claro que no podemos restringir -como se escribió muy a menudo - el uso de las casas funerarias a los pueblos de habla aymara y que la difusión geográfica de aquellas sepulturas no traduce la expansión de los aymaras y/o de su "ideología". Esos sepulcros han sido utilizados por varios pueblos, en varios ámbitos culturales, en medios ambientales muy distintos. No se puede categorizar una "zona chullpa" según un criterio particular, aunque el fenómeno tuvo una manifestación más intensa (en términos de cantidad, de tamaño, de complejidad) en las orillas del lago Titicaca y en el Altiplano 5 .

\footnotetext{
Artículo proyecto ECOS-CONICYT Dinámicas culturales en el Área Centro Sur Andina. Código C06H04 y PICS 4796. CREDAL, Paris III - Sorbonne Nouvelle, Paris, Francia. duchesnefrederic@yahoo.fr

Departamento de Antropología, Universidad de Tarapacá, Arica, Chile. jchacama@uta.cl
} 
Esta costumbre en un territorio dado de erigir edificios chullpa fue compartida por todos los pueblos del área centro-sur de los Andes, y más allá de la cuestión ya muy debatida -sin mayor éxito- del origen y de la difusión de este fenómeno ${ }^{6}$ y de las interpretaciones ligadas a un sitio peculiar, nos parece interesante discutir el "fenómeno chullpario" comparando datos provenientes de regiones muy distintas, pobladas por grupos humanos diferentes y sin relaciones firmes durante el Intermedio Tardío.

Así, este trabajo utiliza y confronta datos provenientes del pueblo de Coporaque (Cañón del Colca, provincia de Arequipa, Perú) y de la quebrada de Chapiquiña (precordillera de Arica, Chile) (Figura 1).

\section{Las chullpas de Coporaque}

El pueblo de Coporaque está ubicado en la orilla norte del río Colca, a más de $3.500 \mathrm{~m}$ de altura, en la provincia de Cayllama. Este pueblo actual se halla al lado de un importante sitio prehispánico llamado San Antonio que fue, según el franciscano Jerónimo de Oré, el mayor lugar de ocupación Inca en esta región. A partir del Intermedio Tardío, Coporaque y la región del Colca fueron ocupados por los Collaguas. Aquel grupo de lengua aymara tiene-según los testimonios de la época colonial-un origen extranjero y hubiera migrado al Colca desde el cerro Velille, ubicado a unos $100 \mathrm{~km}$ al norte, en la actual provincia del $\mathrm{Cuzco}^{7}$. Cuando llegaron los españoles, los Collaguas tenían una fuerte presencia económica y política no solamente en las riberas del Colca, sino también desde las alturas frías de la región hasta los valles bajos en dirección a la costa.

Arriba del actual pueblo de Coporaque y de las ruinas de las antiguas terrazas agrícolas, en la falda oeste de un espolón rocoso de dirección norte-sur, se encuentra un sitio funerario, hoy en día llamado Yuraqaqa. Dos tipos de tumbas comparten el terreno. En el norte del espolón se encuentran 25 pequeñas construcciones semisubterráneas, especie de cuevas

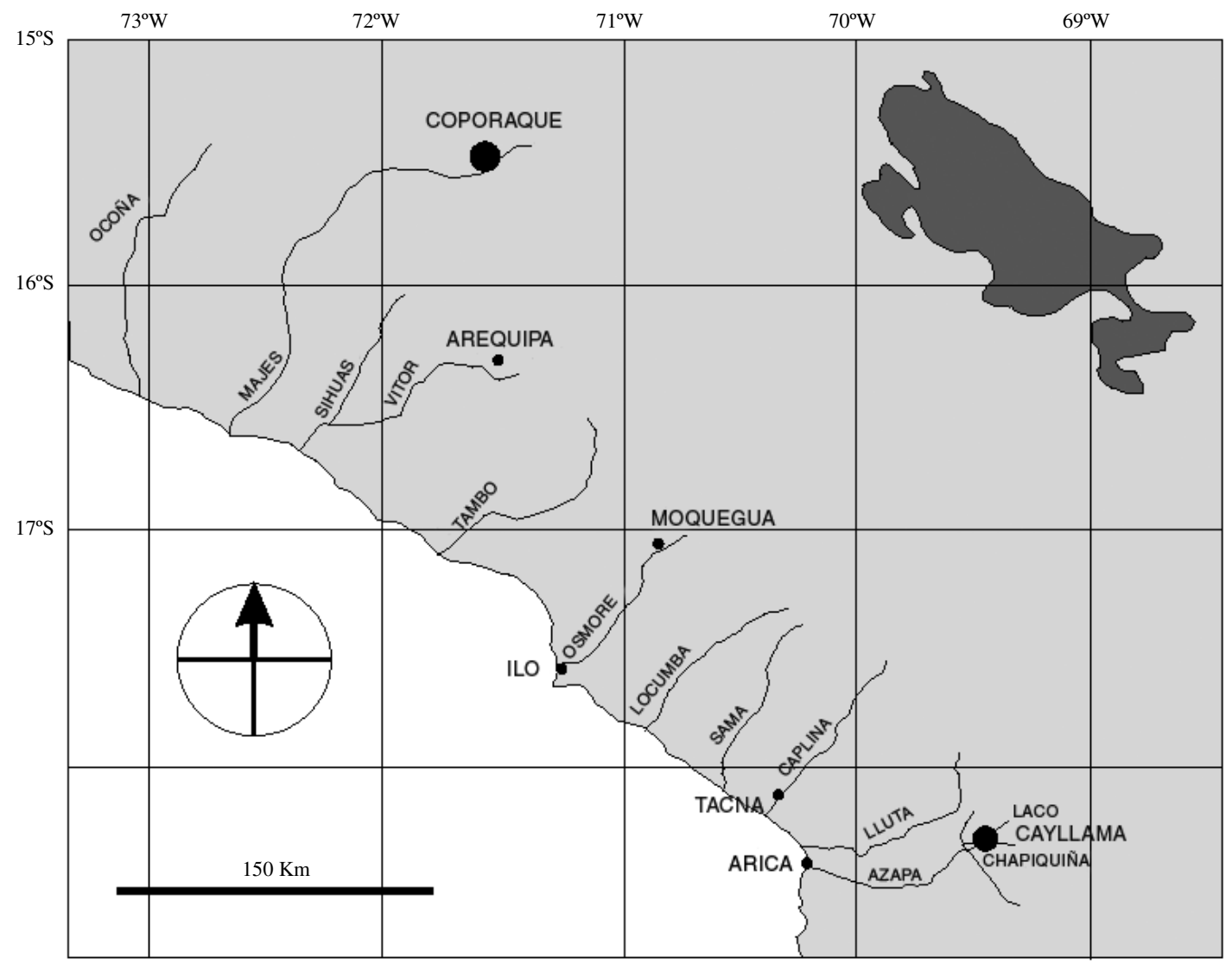

Figura 1. Ubicación de sitios Coporaque y Cayllama. Mapa esquemático sobre base Google Earth. Localization of the archaeological sites of Coporaque and Cayllama. Map based on Google Earth. 
-del tipo "cistas-aéreas"-, edificadas en el talud de la montaña, cerradas por una bóveda de piedras de unos $100 \mathrm{~cm}$ de alto y de ancho, y tapadas por rocas. La extremidad sur del espolón está ocupado, a lo largo de unos $300 \mathrm{~m}$, por 18 tumbas edificadas sobre el suelo, adosadas a la montaña, a manera de "casas funerarias" . Son de plantas cuadrangulares y tienen, de tamaño medio, unos $200 \mathrm{~cm}$ de altura, $300 \mathrm{~cm}$ de largo por $100 \mathrm{~cm}$ de ancho. Los muros tienen entre 30 y $50 \mathrm{~cm}$ de grosor. Todas las tumbas han sido construidas con piedras armadas con argamasa gruesa. En las más completas se pueden observar dos niveles, una cornisa en el nivel superior y varias cámaras funerarias. En algunas, el techo se inicia a manera de falsa bóveda (o intento de falsa bóveda) y el monumento está tapado por largas láminas de piedras. Las tumbas tienen una o varias aberturas de tamaño reducido (aproximadamente $60 \times 40 \mathrm{~cm}$ ) delimitadas por dinteles de piedras. Construidas sobre la falda este del espolón rocoso y apoyadas en su pared, las aberturas de las tumbas están naturalmente dirigidas no solamente hacia el este, sino también hacia el nevado Huarancate. Debido a la importancia de la orientación de los edificios funerarios -muy a menudo hacia el este o un cerro sagrado- es muy probable que este sitio hubiese sido escogido en razón de su orientación "ideal".

\section{Las chullpas de la quebrada de Chapiquiña}

En los altos de la ciudad de Arica se encuentra la precordillera de los Andes con una altura media de 3.000-3.600 msm. Esta zona está atravesada por una serie de pequeños valles precordilleranos que, con dirección este-oeste, alimentan cuatro grandes sistemas fluviales u hoyas hidrográficas: Lluta, Azapa, Codpa y Camarones ${ }^{9}$. En dicha zona se ubica un conjunto de sitios arqueológicos de diferente índole, los cuales son registro de los procesos culturales sucedidos durante los períodos Intermedio Tardío y Tardío (Muñoz y Chacama 2006). Cerca del actual pueblo de Chapiquiña, en la quebrada del mismo nombre, se encuentra el sitio arqueológico llamado "pukara de Cayllama", ubicado sobre una cadena de cerros conocida como cordón Chullpane $(3.250 \mathrm{msm})$ que corren hacia el poniente flanqueados por el norte por la quebrada de Laco Alto y por el sur por la quebrada de Chapiquiña. El sitio se constituye en un estrecho promontorio rocoso, de superficie abrupta, desde el cual se visualizan las dos quebradas arriba mencionadas.
En términos generales, el sitio presenta dos grandes sectores, separados por un muro perimetral que rodea a uno de ellos: el sector residencial. El sector fuera del muro y en cotas más bajas está destinado casi de forma exclusiva a estructuras funerarias, que pueden catalogarse en dos grandes tipos con sus respectivas variantes: "cistas aéreas" y chullpas; estas últimas se distribuyen en dos grandes conjuntos dispuestos en hileras, uno al sur, sobre la quebrada de Chapiquiña, y el otro al norte, sobre la quebrada de Laco Alto; todos sus vanos se orientan hacia el este. Entre ambos conjuntos se encuentra un espacio abierto donde se ubican cuatro hileras de bloques de piedra de regular tamaño (entre 50 y $70 \mathrm{~cm}$ ), separados unos de otros, no llegando a conformar muros.

Las "cistas aéreas" del sitio de Cayllama tienen un patrón circular-pentagonal con muros de piedras de origen volcánico y superficies muy irregulares. Aparentemente la cámara funeraria se cimentó bajo la superficie, mientras que el cuerpo del edificio abovedado se hizo sobre el terreno. Estas construcciones se organizan a modo de células, distribuyéndose desde las cotas inferiores en dirección de la cima. En algunos casos sus muros se consolidan en doble hilada de piedras, rellenas de sedimento y en otros, son bastante simples: grandes piedras lajas dispuestas verticalmente conforman los muros y otra horizontal a modo de cubierta; en algunos casos el conjunto fue cubierto con rocas de menor tamaño, de manera tal que el conjunto de este tipo de sepulturas habría tenido el aspecto de pequeños montículos de piedras.

Por su parte, las chullpas son edificios rectangulares, estructurados a base de barro y piedras lajas sobre un terraplén. Corresponden a 16 las estructuras de este tipo, siendo tres las que se conservan en mejor estado y que nos permiten contemplar su arquitectura. A partir de la estructura mejor conservada, notamos que esta presenta una altura total de $150 \mathrm{~cm}$, ciertamente la altura original. Por otra parte, las diferentes estructuras presentan medidas que van entre 200 y $300 \mathrm{~cm}$ de largo y 120 a $200 \mathrm{~cm}$ de ancho. La técnica constructiva se inicia estableciendo el perímetro rectangular de la cámara, orientado el eje mayor de noroeste a sureste y definiendo su acceso hacia el este. Bloques líticos trabajados a modo de lajas van resolviendo áreas de muro interno; para definir la cámara funeraria las piedras lajas son empotradas de manera vertical en el suelo y horizontal, en 
las paredes; el acceso es definido con otro bloque dispuesto en sentido horizontal, el que cumple la función de dintel. Posteriormente bloques de barro consolidados con fibra vegetal recubren la cámara mortuoria, hasta definir completamente el edificio. El vano de la chullpa mejor conservada se ubica al nivel del piso y alcanza una altura de $70 \mathrm{~cm}$, un ancho inferior de $56 \mathrm{~cm}$ y superior de $41 \mathrm{~cm}$. Un sello cultural de estos edificios lo manifiesta una perforación no muy profunda sobre el dintel, ubicado sobre la parte central de éste, dicha perforación es la impronta de lo que una vez fue un kero de madera empotrado en la cara anterior del edificio. ${ }^{10}$ (Para una mejor comprensión del sitio de Caillama ver: Muñoz, 2007, 2012; Muñoz y Chacama 2006; Romero 2002, 2003).

\section{Problemáticas}

Los sitios funerarios de Coporaque y de Chapiquiña, pueblos alejados casi $400 \mathrm{~km}$ (en línea recta) y provenientes de contextos culturales y geográficos muy distintos, reflejan muy bien la realidad del "fenómeno chullpario": una gran heterogeneidad dentro de una manifestación similar. De una manera formal, como ya lo había notado al inicio del periodo colonial el padre Bartolomé de Las Casas ${ }^{11}$, las chullpas o casas funerarias tienen formas arquitectónicas variadas: pueden ser cuadradas o redondas, tener uno o dos pisos, tener una o varias cámaras, estar hechas de piedras o de adobes. La tipología de las chullpas $^{12}$ es compleja y las diferencias arquitectónicas tienen ciertamente un sentido y un valor profundo, ya que, entre otros, reflejan la identidad de sus constructores en el sentido de que existe una relación estrecha entre los estilos arquitectónicos y los territorios étnicos -hecho ya descrito por el cronista Bernabé Cobo ${ }^{13} \mathrm{y}$ comprobado por investigaciones recientes (Kesseli y Pärssinen 2005).

Pero más allá de las diferencias, el uso de aquellas estructuras muestra una misma manifestación, tal vez una misma necesidad, frente a la muerte y a los muertos: dejar una marca fuerte en el espacio y a los ojos de los sobrevivientes, dejar la posibilidad a los sobrevivientes de seguir teniendo una conexión física con los muertos, ¿por qué?, ¿para qué? Las funciones de dichos edificios ha sido un tema ya muy debatido y a pesar de las divergencias en las interpretaciones, ya nadie pone en duda que esos monumentos -y no solamente porque son tumbasparticipan del culto a los antepasados. Tratar del "fenómeno chullpario" es tratar sobre el papel la función de los antepasados en la sociedad a través de su manifestación monumental y espacial. Más que sepulturas, más que lugar de culto ceremonial, estos monumentos son considerados como moradores, marcadores de presencia, como signos de distinción personal o étnica, como manifestación externa de la organización social. El cuadro siguiente muestra las diferentes interpretaciones a propósito de las funciones de las chullpas:

\begin{tabular}{ll}
\hline Función secular & \\
\hline $\begin{array}{l}\text { Habitación } \\
\text { Silo } \\
\text { Marcador territorial }\end{array}$ & $\begin{array}{l}\text { Posnansky 1918; Bandellier 1910 (en Mc Bain 1959); Vásquez et al. 1935; Gutiérrez 1935 } \\
\text { Bandelier 1910; Sarracino 1979 } \\
\text { Hyslop 1977, Gill 2001a, 2001b }\end{array}$ \\
\hline Función Ceremonial & \\
\hline Cámara funeraria & $\begin{array}{l}\text { Ayala 2001; Franco 1937; Gill 2001a, 2001b; Hyslop 1977; Isbell 1996; Lumbreras 1974; } \\
\text { Nordenskiöld 1956; Ryden 1947; Squier 1974 }\end{array}$ \\
Lugar ceremonial & $\begin{array}{l}\text { Aldunate et al. 1979; Aldunate y Castro 1981; Ayala 1998, 2000; Berenguer et al. 1984; } \\
\text { Gutiérrez 1935; Hyslop 1977; Isbell 1996; Latcham 1915; Squier 1974; Vásquez 1935 }\end{array}$ \\
\hline Función Política-social & $\begin{array}{l}\text { Heredia 1993:164-165; Hyslop 1977; Gisbert 2001:17; Gisbert et al. 1996:20; Muñoz et al. } \\
\text { 1977a; Romero 2001, 2002; Santoro et al. 2003; Sagárnaga, 1993:38; Wernke 2003; Pärssinen y } \\
\text { Sepulcros para la elite }\end{array}$ \\
$\begin{array}{l}\text { Castro et al. 1984; Gill 2001a, 2001b; Isbell 1996; Romero 2002; Pärssinen y Kesseli 2005 } \\
\text { Isbell 1996 }\end{array}$ \\
$\begin{array}{l}\text { Marcador de presencia } \\
\text { Organización social }\end{array}$
\end{tabular}


Obviamente, todas estas proposiciones no se contradicen entre ellas: la muerte -siendo un hecho social total- es un fenómeno que abraza realidades tanto religiosas y simbólicas como políticas y económicas. A la luz de las diferencias y similitudes de nuestros sitios y según lo que pueden aportar al debate, vamos a discutir aquellos puntos claves para descifrar lo que las chullpas enseñan acerca de las sociedades que las edificaron. Más aún, importa considerar que durante el Intermedio Tardío varios grupos de los Andes como los de Coporaque en el sur de Perú y de Chapiquiña en el norte de Chile reunieron las condiciones necesarias para aceptar y utilizar un nuevo tipo de sepulturas y que este uso fue lo suficientemente duradero en el tiempo para crear una costumbre. Así, nos debemos preguntar si este rasgo cultural que caracteriza un hecho tan importante y estructurante como la muerte traduce o no una uniformidad de las prácticas funerarias y de las actitudes frente a la muerte; una uniformidad o no del rol y de las funciones de la muerte dentro de aquellas sociedades tan diferentes. Y considerando que las creencias hacia la muerte y las prácticas funerarias constituyen un fuerte revelador cultural y un reflejo de las sociedades, nos debemos preguntar si esas casas funerarias manifiestan cierta homogeneidad cultural en los Andes del Centro-Sur.

\section{Chullpas y organización social}

Es algo común que la sociedad de los muertos sea percibida como un reflejo de la de los vivos y se estima a menudo que la jerarquía social se refleja en la muerte y en el más allá. Así las tumbas monumentales y los ajuares funerarios suntuosos son considerados como signos de distinción y como indicadores de enterramiento de personas de alto rango social.

La monumentalidad de las chullpas, a veces adornadas, la cantidad relativamente escasa de sitios encontrados, en proporción a los sitios de habitación, hace que la mayoría de los estudios consideren e interpreten aquellos edificios como sepulcros de la élite. Los señores Lupacas (Hyslop 1977), Pacajes (Pärssinen y Kesseli 2005) o Carangas (Gisbert 1994), por ejemplo, habrían sido depositados en grandes torres destinadas a magnificar al difunto y a simbolizar su prestigio y su poder. Varias crónicas pueden apoyar esta idea. Así Pedro Cieza de León escribe que las torres funerarias del lago Titicaca pertenecían a señores locales:

Apartados de estos edificios [de Tiwanaku], están los aposentos de los incas, y la casa donde nació Mango Inga hijo de Guaynacapa, y están junto a ellos dos sepulturas de los señores naturales de este pueblo, tan altas como torres anchas y esquinadas, las puertas al nacimiento del sol (Cieza de León 1988 [1553]:235). [...] ponían tanto cuidado en labrar y adornar los sepulcros en que se habían de enterrar, como si en eso sólo estuviera toda su felicidad. Lo mismo guardaban estos indios peruanos, y con más cuidado, gusto $\mathrm{y}$ curiosidad que ninguna otra gente deste Nuevo Mundo, poniendo la presunción y honra en que sus enterramientos y sepulturas fuesen con la mayor suntuosidad, grandeza $\mathrm{y}$ fasto posible, conforme a la calidad de sus dueños. (Cobo 1964 [1653]:270)

El hecho, atestado por las crónicas y la arqueo$\operatorname{logí}^{14}$, que las chullpas eran sepulturas colectivas -volveremos sobre este punto-, podría también apoyar la interpretación "elitista", ya que se considera que los mallkus o curacas iban al más allá acompañados por familiares o servidores que eran sacrificados durante su funeral y depositados a su lado en el sepulcro. Bartolomé Álvarez atestigua, a finales del siglo XVI, sobre esta práctica en el área sur del lago Popó y en otras áreas de los Andes del Centro-Sur, tal como Chuquibamba ${ }^{15}$ :

Solían los curacas principales, cuando moría algún principal curaca, hacer que en el aposento del muerto se encerrasen las mancebas que habían sido de aquel que estaba muriendo. A las cuales las cercaban otras mujeres; dándoles a comer coca y a beber acua, las hacían morir borrachas y ahogadas desta comida y bebida, diciendo "come, come y bebe presto y mucho, que has de ir a servir al malco -que quiere decir "señor"-; está de partida y has de ir a servirle allá donde va; que, si tú no vas, no lleva quien le sirva". Y así mataban a muchas, y las enterraban con ellos en sus sepulcros (Álvarez 1998 [1588]:94).

Después que yo estoy en este reino, lo he oído decir en dos partes que lo han hecho 
curacas, y ha habido sospecha dello y se ha murmurado. Lo uno fue en un pueblo que se dice Calamarca; lo otro en el obispado del Cuzco, en un pueblo que se dice Chuquibamba (Álvarez 1998 [1588]:94).

Los contados estudios que suscitaron las chullpas de la precordillera de Arica y en la zona de Arequipa llegaron a las mismas interpretaciones. Por ejemplo, según Romero (2002), las chullpas de Cayllama que nos ocupan en este artículo habrían pertenecido a curacas importantes provenientes del señorío aymara Caranga ${ }^{16}$. Del mismo modo, Steve Wernke (2003), quien hizo un amplio estudio arqueológico sobre los Collaguas, considera las casas funerarias como sepulcros de gente de alto rango.

Sin embargo, como ya lo habíamos subrayado en un precedente artículo (Duchesne 2005), esta hipótesis se ha vuelto a lo largo del tiempo y de los estudios una afirmación, casi un axioma, sin que se haya hecho una demostración con argumentos comprobantes. En realidad, las evidencias son muy pocas y resulta difícil -y a menudo artificial- extrapolar datos arqueológicos e históricos de sitios provenientes sobre todo del altiplano a todos los edificios tipo chullpa de los Andes del Centro-Sur. Datos de crónicas poco utilizados (ya que no validan esta interpretación "elitista") y nuestros dos sitios de Coporaque y de Cayllama -contrariamente a los análisis de Romero y de Wernke- muestran que no se puede aceptar tan sencillamente que todas las chullpas fueron sepulcros de la élite.

A propósito de las torres funerarias, Cieza de León y Bartolomé Álvarez hacen una clara distinción según el tamaño:

[...]en la provincia de Collao, las hacen [las sepulturas]en las heredades, por su orden, tan grandes como torres, unas más y otras menos, y algunas hechas de buena labor (Cieza de León 1988 [1553]:164).

Los sepulcros eran levantados en alto, en cantidad de estado y medio, más o menos según la dignidad del difunto y su nobleza, y según el valor de la gente o de su linaje que lo enterraba (Álvarez 1998 [1588]:92).

El cura de Ullaga deja entender que el entierro en chullpas no era una prerrogativa de gente de alto estatus y que el uso de aquellas estructuras era difundido entre todos los indios; y por tanto, el tamaño de la chullpa variaría según el rango social. Del mismo modo, varios cronistas, al referirse al uso de las torres o casas funerarias, hablan simplemente de "los Indios" y pocas veces afirman claramente un uso reservado a "señores". Además, algunos cronistas atestiguan en los siglos XVI y XVII la presencia de grandes cantidades de torres. Así, un siglo después de la llegada de los españoles (o sea, cuando ya numerosas chullpas habían sido destruidas por el celo extirpador de los invasores), Antonio Vázquez de Espinosa afirma que en la provincia de Huanuco "hay muchos pueblos despoblados de los antiguos y en ellos y aquellos cerros muchas sepulturas de ellos a modo de torrecillas" (Vázquez de Espinosa 1969 [1629]:330) y que en los campos de la provincia de Omasuyo "hay gran cantidad de torrecillas que son los sepulcros de los antiguos" (Vázquez de Espinosa 1969 [1629]:407). Veinte años más tarde, Bernabé Cobo atestigua que "destas sepulturas grandes como torres usaban los Collas y hay tantas por todas las provincias del Collao" (Cobo 1964 [1653]:273). Sin duda, se redujo de manera drástica el número de chullpas y las que vemos en pie hoy en día no son más que la mínima parte de las que existían anteriormente ${ }^{17}$. Así -y a pesar de que las estructuras "tipo chullpas" detectadas por los arqueólogos, especialmente en la precordillera de Arica (Muñoz y Chacama 2006), quedan mínimas respecto a los sitios residenciales, domésticos y a otro tipo de estructura funeraria (que analizaremos más adelante)-podemos postular que las tumbas sobreelevadas en determinadas zonas de los Andes eran un modo común y difundido de entierro. Torres o torrecillas funerarias no caracterizan automáticamente y únicamente el entierro de una persona de alto rango y los indios del común no eran sistemáticamente enterrados bajo tierra como aún a menudo se señala, siguiendo el ejemplo del trabajo de Steve Wernke sobre los Collaguas: "Clearly, chullpas were reserved for high status individuals. Most commoners probably continued to be interred in the subterranean, rock-lined tombs" (Wernke 2003:227). La distinción se hacía por las diferencias de tamaño, de estilo - por toda una gramática que todavía queda por entender- $\mathrm{y}$ obviamente por los ajuares funerarios.

Entonces, ¿podemos pensar, sencillamente, que las grandes chullpas ornadas revelan sepulcros de señores y que las pequeñas "torrecillas", como dicen las fuentes previamente citadas, eran para la gente del común? Las chullpas monumentales y decoradas de los carangas se hallan en el corazón del mundo Caranga, cerca del río Lauca, hoy en Bolivia (Gisbert 
1996, 2001). Las de Chapiquiña, al igual que todas las de la precordillera de Arica - una periferia de la zona de influencia Caranga-, son muy modestas y muy sencillas en su construcción. Las chullpas de la zona "nuclear" del Lauca serían entonces las de los señores y las de Chapiquiña ilustrarían una ocupación y una utilización del sitio por gente de menor rango en la jerarquía social Caranga.

Del mismo modo, las grandes torres funerarias descritas en el siglo XIX por el viajero Paul Marcoy (2001) en su caminata a través las alturas de las tierras Collaguas, o sea el territorio "nuclear" y de origen de los pastores Collaguas, contrastan con las casas funerarias de Coporaque, localizadas en el valle del Colca, tierra agrícola y periférica de migración o, más bien, de "colonización":

El refugio que acabamos de descubrir tan oportunamente era una construcción de bloques enormes, cubierta por uno monolítico. Una pequeña ventana, a la altura de un hombre, y orientada hacia el oriente, apenas si alumbraba el interior. El sepulcro, pues se trataba de uno, podía tener unos diez pies cuadrados por ocho de altura. Sus muros en talud, como los de las construcciones egipcias, y de un enorme espesor, probablemente habían visto pasar muchos siglos y soportado muchas tempestades (Marcoy 2001 [1869]:135). Sus tumbas, llamadas chullpas, tenían la figura de una pirámide truncada de veinte a treinta pies de altura (Marcoy 2001 [1869]:138).

Se destaca netamente en la geografía funeraria una división espacial franca entre precordillera/valle y altiplano que puede corresponder a la geografía sociopolítica, la monumentalidad de las chullpas siendo mucho más marcada en las zonas de mayor importancia o de ocupación más remota. Si tal hipótesis se confirma, se podrían leer a través de la cartografía estilística de las chullpas las lógicas de ocupación del espacio y de las divisiones jerárquicas internas de las etnias; proposición que se puede combinar con los trabajos de Durston e Hidalgo (1999) e Hidalgo y Durston (1998), respecto a la "verticalidad escalonada" que implica centros políticos de 1er, $2^{\circ}$ y $3^{\text {er }}$ orden.

Esta distinción arquitectónica, notable al nivel regional, se encuentra también dentro de un mismo sitio; distinción que puede también reflejar diferencias sociales jerárquicas al nivel local. En Chapiquiña como en Coporaque hay dos tipos de sepulturas: las chullpas y las tumbas "cistas aéreas". La tradición de entierros en cistas se encuentra presente en valles bajos desde temprana data, con la diferencia de que estas no son aéreas ya que el terreno permite realizar excavaciones y en ocasiones "encistarlos" con piedras. Según las dataciones obtenidas, las primeras ocupaciones de la precordillera de Arica se producen alrededor del X al XI milenio d.C. por poblaciones de valles occidentales portadores de una tradición de cistas. Hacia el año 1200, 1250 se presentan las primeras evidencias de poblaciones altiplánicas, portadoras de una tradición de chullpas (Muñoz y Chacama 2006). Por lo anterior podemos suponer que la tradición de cistas en la sierra de Arica es previa a la tradición de chullpas. Sin embargo, que las cistas tengan un inicio previo no implica que se dejaran de usar cuando se inició el uso de las chullpas, llegando a convivir ambos tipos de estructuras funerarias.

De un punto de vista estrictamente formal, la diferencia más significativa entre aquellas tumbas reside en el hecho que la chullpas son abiertas mientras las tumbas "cistas aéreas" son tapadas (¿selladas?). Pero al igual que las chullpas, y aunque sean semisubterráneas (o más bien semisobreelevadas), las tumbas "cistas aéreas" son visibles en el espacio e ilustran una misma necesidad obsesiva de marcar el territorio por los muertos. O sea, que ambas estructuras pertenecen a la misma dinámica cultural e histórica, quizás al mismo "momento ideológico", y se puede suponer un uso contemporáneo de los dos tipos de tumbas. Si seguimos las observaciones arriba mencionadas para aplicarlas al nivel local, las tumbas "cistas aéreas" corresponderían a entierros de gente de menor estatus mientras las torres funerarias servían de sepulturas para personas más ilustres.

Continuando el análisis de las diferencias notables entre los monumentos funerarios, notamos que el conjunto chullpario de un mismo sitio no es uniforme sino que los sepulcros muestran diferencias de tamaño y de complejidad. En el sitio de Coporaque -en Chapiquiña el estado de conservación no nos permite considerar con precisión las diferencias- cinco chullpas están aisladas y entre aquellas, una, la tumba 10 , se destaca de las otras por ser la única cuyos cadáveres muestran deformaciones craneales $^{18}$. Las demás chullpas están agrupadas 
en tres conjuntos distintos: un primer grupo de tres chullpas de dimensiones modestas, un segundo grupo de tres chullpas "verticales" (más altas que anchas) más complejas con dos pisos, un tercer grupo compuesto de siete chullpas "horizontales" (más anchas que altas) con varias cámaras.

Esta organización -obviamente conscienteresponde a una cierta lógica y tiene un sentido profundo que refleja realidades sociales de los Collaguas. Según Ulloa de Mogollón, la sociedad Collagua estaba dividida en tres grupos clasificatorios y jerárquicos: Collana, Pascana, Cayao ${ }^{19}$. El cronista precisa que esta organización proviene del periodo incaico, pero sabemos que entonces se respetaron las organizaciones locales -lo que da cuenta de la coexistencia de una multidud de estructuras sociales en los Andes durante el Tawantinsuyu (Pärssinen 1992). Así es probable que aquel tripartismo preexistió a los Incas durante el período Intermedio Tardío cuando se edificaron las chullpas. ¿Podemos ver un paralelismo entre los tres grupos de chullpas y esta organización tripartita? Por su parte, el sitio Cayllama tiene dos grandes sectores: uno residencial en torno a un gran promontorio y el sector funerario en un sector plano situado fuera y frente al sector habitacional. A su vez, el sector de enterratorios presenta dos sectores bien definidos con presencia de chullpas y cistas cada uno. Uno al borde norte sobre la quebrada de Laco y otro al borde sur sobre la quebrada de Chapiquiña, ambos conjuntos están dispuestos casi en hilera; entremedio de ambos, y en la pequeña pampa que los separa, se encuentran cuatro hiladas de grandes piedras en forma perpendicular a los dos sectores de chullpas $^{20}$. ¿La macrodivisión del sitio podría del mismo modo reflejar la organización dual ${ }^{21} \mathrm{de}$ la sociedad Caranga?

Sin poder precisar mucho el análisis e ir más allá de un esquema simplista, notamos de nuevo una correspondencia entre la organización social y la geografía de los cementerios. Los Collaguas de Coporaque y los Carangas de Chapiquiña tenían, según su grupo, su rango, su estatus, un lugar preciso de entierro en la necrópolis y cada lugar se diferenciaba de los demás de manera significativa, respondiendo a lógicas intrínsecas de distinción. Documentos coloniales vienen apoyando esta hipótesis.

Las Casas escribe que " [...] en algunas provincias dellas hacían para sepulturas unas torres altas [...] y cada uno tenía la sepultura de su abalorio y linaje" (Las Casas 1967 [1552-1561]:571). Así -y es un rasgo que permanece durante la época colonial-podemos considerar las chullpas como lugar privilegiado del culto a los antepasados, como mausoleo "familiar", o más bien de un grupo de parentesco, y que la calidad de aquellos grupos era significada precisamente por su localización en la geografía de la necrópolis, además de la arquitectura de las tumbas - el tamaño de las chullpas variando según el rango del individuo o del linaje como lo notó Bartolomé Álvarez.

El carácter "familiar" de las chullpas viene a aclarar el hecho que dichas tumbas, en ocasiones, son colectivas, como lo atestiguan las que no fueron totalmente saqueadas ${ }^{23}$. Ya lo hemos mencionado, personas de alto estatus podían ser acompañadas en el más allá por familiares o servidores sacrificados y depositados en la misma tumba. Pero los sacrificios no explican todo como lo muestra Álvarez:

En la baja bóveda de este sepulcro enterraban [a] los nobles, y con ellos sus sacrificios. [...]en la bóveda de arriba ponían todos los muertos -asentados los curacas en sus sillas y los demás sin ellas-, vestidos [de] sus ropas como cuando eran vivos, con toda su autoridad, cubiertas sus cabezas con su traje de plumajes [y] paras -que es cosa como patena que traen sobre la frente- redondas o largas que llegan sobre las cejas, de oro o de plata o de azófar; cada uno con su modo de caperuza, como solían andar (Álvarez1998 [1588]:93).

Así, la "colectividad" de las chullpas no puede ser interpretada solamente como el resultado de los sacrificios de los acompañantes de un curaca. Una misma chullpa servía para varios difuntos, para varios enterratorios funerales, era compartida entre miembros de un mismo linaje y/o personas de diferentes rangos sociales; la jerarquía social reflejándose, según Bartolomé Álvarez, en la disposición de los cadáveres dentro de la tumba. A través de las chullpas, los diferentes niveles jerárquicos de una sociedad se "encajan" los unos en los otros a manera de matrioshka: distinción entre los individuos en la chullpa, distinción entre las chullpas, distinción entre los grupos de chullpas dentro de un sitio, distinción entre los sitios al nivel regional; lo que representan cabalmente las sociedades andinas como "sociedades segmentarias" tal como las definen los antropólogos. 
Además, si pensamos de dicho modo la colectividad mortuoria de una chullpa, debemos suponer que los cuerpos de una chullpa no eran depositados simultáneamente de una sola vez, sino de manera sucesiva y tal vez durante un periodo largo. Esto nunca fue averiguado por dataciones radiocarbónicas, pero la construcción misma de las casas funerarias de Coporaque muestra probablemente una utilización y una(s) reutilización(es) de las sepulturas a lo largo del tiempo. Eso lo podemos ya suponer por el hecho mismo de que esas sepulturas son abiertas, pero hay más. Las chullpas tienen varias cámaras, dispuestas de manera horizontal, vertical o ambas. Algunas chullpas de Coporaque muestran obviamente -en particular la chullpa 1-que las cámaras no han sido edificadas en un mismo momento sino en varias etapas en el tiempo. Además, en algunos edificios una cámara puede venir tapando otra-aunque esté llena de cuerpos-hasta impedir su acceso y, por lo tanto, el culto físico a los muertos. Insistamos en el hecho, fundamental nos parece, de que ninguna cámara sellada fue vaciada por sus constructores. Las chullpas de Coporaque han sido construidas a lo largo del tiempo, sumando, según las necesidades o cambios, nuevas cámaras al núcleo básico para depositar nuevos cadáveres. Las chullpas tenían una utilización de larga duración, obviamente como lugar de culto, y también como lugar de entierros sucesivos para individuos de un mismo linaje.

Las chullpas de Chapiquiña, más sencillas, tienen una sola cámara y han sido encontradas vacías. Además, son más pequeñas, por lo que puede caber la posibilidad de que correspondan a sepulturas individuales. Sin embargo, y siendo un sepulcro abierto, el hecho que una chullpa sea "individual" no significa objetivamente un uso único y puntual y no contradice una utilización y una reutilización de larga duración. Los cronistas son poco locuaces sobre este punto clave; sólo Huaman Poma de Ayala, al dibujar entierros en chullpas, dejó un indicio: representó a muertos recientes, sin ninguna marca de alteración física, a punto de ser depositados en chullpas de tamaño modesto ocupadas ya por un cadáver reducido al estado de esqueleto, o sea ocupando la tumba desde cierto tiempo. Esto deja entender claramente que las chullpas no tenían un uso único, sino que se volvían a utilizar para depositar nuevos muertos a lo largo del tiempo.

Entonces, si consideramos, como lo acabamos de mencionar, que la organización social se refleja en la geografía de las necrópolis, podemos interpretar las chullpas como sepulturas de un grupo humano preciso y que servían a lo largo del tiempo para varias generaciones. Cada grupo humano tendría un lugar asignado según su importancia social y dentro de la sepultura la jerarquía de aquel grupo era respetada y notificada; entendiendo por grupo humano una estructura de linaje, tal como Las Casas y Álvarez hablan de "sepulturas de linaje" de la misma manera que otros documentos coloniales ya citados.

Es un hecho que las chullpas son un lugar de entierro y de culto donde los sobrevivientes rinden culto a sus antepasados, pero si las consideramos efectivamente como lugares ligados a un linaje $-\mathrm{y}$ entonces a los intereses de aquel linaje- debemos considerar las chullpas no solamente como lugar de importancia religiosa y simbólica, sino también política.

\section{Chullpas, migración y legitimación}

El inicio del Intermedio Tardío, antes de la afirmación de las entidades regionales tales como los señoríos Lupaca, Pacajes, Carangas, está marcado por olas de migraciones. Varios documentos coloniales relatan movimientos de población en los Andes del Centro-Sur. Por ejemplo, Mercado de Peñalosa atribuye a los Pacajes un origen lejano, ajeno a su lugar de expansión durante el Intermedio Tardío:

Los cuales dichos indios Pacaxes dijeron los indios antiguos haber tenido su origen, unos de la una parte de la laguna de Chucuito y otros de hacia la parte de los Carangas de donde salieron y poblaron en esta provincia en los cerros más altos que hay en ella (Mercado de Peñalosa 1965 [1586]:337).

Esas migraciones de poblaciones de alturas fueron frecuentes durante el Intermedio Tardío, por lo menos en los Andes meridionales. Augusto Cardish ha demostrado que en el siglo XIV una deterioración climática se produjo en los Andes centrales (Cardish 1975). Indicaciones análogas se encuentran en la región del lago Titicaca durante la misma época. Duviols piensa -a partir de mitos recogidos por los extirpadores de idolatrías del siglo XVII- que en los Andes centrales los Llacuaces, pastores de la puna, habrían "bajado" hacia los valles agrícolas de esta región durante la 
misma época para instalarse en contacto con los Huaris, agricultores locales (Duviols 1973). Por su parte, Rivière (1982), a partir de documentos del siglo XVIII, señala que los pueblos de las cabeceras de valles en el actual territorio chileno dependen de los Carangas, citando entre ellos "Pachica, Esquina, Guallatire, Pucyo, Tignamar, Belén" (Rivière 1982:19). Dicha dependencia se habría iniciado durante épocas prehispánicas, perdurando hasta tiempos coloniales. Estudios arqueológicos llevados a cabo en la precordillera de Arica durante las últimas décadas convalidan las propuestas provenientes de la Etnohistoria (i.e Muñoz y Chacama 2006; Romero 2003).

Nuestros dos sitios de Coporaque y de Chapiquiña se inscriben también en un similar contexto. Ulloa de Mogollón escribe acerca de los Collaguas que habrían "bajado" de su lugar mítico de origen, un volcán de la provincia del $\mathrm{Cuzco}^{24}$, para poblar las orillas del Colca.

Unos se llaman collaguas; llámanse desta manera por antigualla; tienen para sí de noticia que se dan heredada de padres a hijos, que proceden de una guaca o adoratorio antiguo questá en los términos de la provincia de Vellilli, comarcana desta, ques un cerro nevado a manera de volcán, señalando de los otros cerros que por allí hay, el cual se llama Collaguata (Ulloa de Mogollón 1965 [1586]:327).

Del mismo modo, como ya lo hemos señalado, la precordillera de Arica conoce al inicio del Intermedio Tardío movimientos de población que además fueron los primeros de importancia en esta región, ya que la ocupación humana empieza a tener cierta importancia solamente a partir de 1.000 d.C. con la expansión, en principio, de las poblaciones de valles bajos $\mathrm{y}$, posteriormente, a partir del siglo XII, por poblaciones altiplánicas, en particular los carangas. Sus desplazamientos hacia los valles occidentales y la costa habrían sido motivados por la necesidad de controlar espacios necesarios a la recolección o a la apropiación de recursos naturales existentes en dichos espacios, en una época de prosperidad; prosperidad notable, durante el Intermedio Tardío, por una multiplicación, una diversificación y una complejización de los ajuares funerarios ${ }^{25}$. Estaríamos entonces ante una “colonización" de los valles serranos, por parte de diversas etnias altiplánicas, incluidas en ellas la etnia Caranga, a través de pequeños grupos que poblaron de manera salpicada las cabeceras de las diferentes cuencas hidrográficas del norte de Chile, en la vertiente occidental de la Cordillera de los Andes. Sitios representativos de este proceso son los sitios de Chapicollo 1 y 2 en el valle de Zapahuira; Laco alto y bajo en el valle de Laco; Cayllama y Pujone en el valle de Chapiquiña; Huaihuarani, Trigalpampa, Incaullo en el valle de Belén, entre otros (Muñoz y Chacama 2006). Tales movimientos de población provocaron ciertamente conflictos bélicos, lo que los arqueólogos evidencian a través de la presencia de pukaras, poblados defensivos construidos durante el Intermedio Tardío, que insinúan una cierta inestabilidad política, y que encontramos en gran cantidad tanto en la precordillera de Arica como en las cuencas del $\mathrm{Colca}^{26}$.

Es durante esta época de conflictos que aparecen en los Andes del Centro-Sur las chullpas y la necesidad de marcar el territorio con la muerte y por los muertos. Dentro de este contexto de prosperidad y de apropiación, de migración y de expansión, los grupos colonizadores debían imponer su autoridad sobre el espacio y mantenerla en el tiempo, y en este juego de poder las chullpas tuvieron un papel de primera importancia. Su función funeraria y de lugar de culto a los antepasados implica una atención y una presencia regular del grupo o de la comunidad que las edificó -aún más si consideramos las chullpas como sepulturas de linaje que servían para varias generaciones; en dicho sentido, las chullpas, como ya lo pensaba J. Hyslop (1977), pueden ser consideradas también como marcador de "propiedad" del territorio, que permitiría la legitimación de las apropiaciones hechas por un grupo y su reproducción en el tiempo a partir del culto a los antepasados. Al mismo tiempo, las chullpas y su contexto reforzaban la unidad de una comunidad y aseguraban de algún modo su continuidad en el tiempo, como Isbell lo planteó en su modelo "ayllu de sepulcros abiertos"27. Entendido esto, las chullpas de Coporaque y del Colca -lugar de migración y de instalación de los Collaguas- pueden ser vistas como mojones y, del mismo modo, las chullpas de Chapiquiña podrían haber cumplido con una doble función: fuera de su condición de sepultura, habrían servido también como marcadores de los límites de la influencia Caranga hacia el occidente, reforzando la influencia de los miembros aymaras de la comunidad de Cayllama. 
Las chullpas fueron en sí un vector del enraizamiento del grupo en el territorio y, dentro de una lógica de apropiación/legitimación, permitían la creación de una "autoctonía" que, a través del culto a los antepasados, daba una legitimidad firme en aquel territorio a lo largo del tiempo. La tierra de migración se vuelve por este proceso tierra de origen. Efectivamente, si consideramos que las aperturas de chullpas -o sea su "punto de comunicación"- están frecuentemente dirigidas hacia el este o hacia los nevados y volcanes sagrados, lugares comúnmente considerados como el origen mítico de diversos grupos humanos, podemos postular que las chullpas se convertían, a lo largo del tiempo, no solo en lugares de culto sino también en substituto al lugar de origen del grupo reproduciendo, simbólica y materialmente, el lugar de origen y de procedencia del primer ancestro mítico original comúnmente llamado pacarina. En este sentido, un sitio de tumbas sobreelevadas podría ser calificado de "lugar de memoria" tal como lo definió el historiador francés Pierre Nora ${ }^{28}$.

Más allá, y a título de hipótesis, podemos suponer que la chullpa en sí, considerada como un "colectivo ancestral", y más aún el lugar de edificación de la chullpa, elegido en total coherencia con el espacio sagrado, tenía para el grupo y en el aspecto performativo del ritual funerario y de los rituales memoriales una importancia mayor que los difuntos mismos, o más bien que los cuerpos de los difuntos, cuya importancia ritual obvia durante la época colonial no corresponde necesariamente a la de los tiempos prehispánicos. Dentro de nuestra interpretación "colectiva" y "no elitista" de la muerte y del uso de las chullpas, el individuo quedaba eclipsado por la comunidad enraizada gracias a la legitimación que da la muerte no solamente en el territorio, sino también en los tiempos: pasado, presente y futuro, lo que va cambiando durante la época colonial cuando el culto a los muertos, frente a la desestructuración política, social, cultural y a la evangelización de las sociedades andinas, se vuelve cada vez más secreto, individual, privado, orientado hacia la persona antes de todo ${ }^{29}$.

\section{Conclusión}

En Coporaque y en Chapiquiña, como en todos los Andes del Centro-Sur durante el Intermedio Tardío, diferentes pueblos se apropiaron de un mismo y nuevo tipo de sepulturas colectivas, visibles, abiertas. Esta apropiación, reflejo de cambios y de nuevas necesidades comunes a los pueblos de aquella región, creó sin duda nuevas "costumbres". A través de las chullpas que cubren todos los Andes del Centro-Sur, sobre todo las zonas de altura y las cabeceras de valles (pero también, en menor medida, en zonas costeras) (Trimborn 1969), y considerando las implicaciones deducidas de esta misma "manera de hacer", tenemos el indicio de una concepción funeraria común, lo que nos permite pensar en la muerte como un factor cultural bastante homogéneo dentro de toda esta zona. Por supuesto esto no quiere decir que consideremos esta amplia región como un grupo cultural uniforme; por ejemplo, los gestos y ritos funerarios, o sea las prácticas funerarias stricto sensu, que se nos escapan por falta de fuentes y de material arqueológico, eran sin duda muy distintos de una zona a otra. Pero, más allá de las diferencias y particularidades entre esta multitud de pueblos, una misma concepción de la muerte podía unir, dentro de un cierto entendimiento cultural, las poblaciones prehispánicas de los Andes del Centro-Sur y, sin duda, dentro de un contexto general caracterizado por la inestabilidad política, migraciones y la afirmación de entidades regionales. El uso compartido de estructuras funerarias similares, en su arquitectura y sobre todo en sus funciones, traduce una manera similar de utilizar la muerte en sus significados sociopolíticos, haciendo de los muertos y de los antepasados, los dueños del suelo del territorio, permitiendo a los vivos perpetuar su legitimidad en el espacio y en el tiempo.

La aparición de las chullpas en el Intermedio Tardío corresponde a un nuevo momento en la historia política de los Andes dentro del cual los muertos llegan a tener un papel fundamental para el grupo. Esto, claro, no quiere decir que dicho culto surgiera en ese momento, pero sí que este llega a tener una nueva importancia, ya que un muerto cualquiera del común, al integrarse en un "colectivo ancestral" y como una parte del todo, se pone visible en el entorno y llega tener un papel importante en el espacio físico y sagrado, cuando lo visible del espacio había sido hasta aquel entonces ocupado exclusivamente por dioses y señores principales ${ }^{30}$. Así, la aparición de las chullpas corresponde a la entrada en la escena de la muerte y de los muertos -y ya no de alguien en particular- en su papel fundamental de protectores, de fecundadores, de reproductores de la sociedad. 
Agradecimientos: Este artículo es resultado de los proyectos: "Dinámicas culturales en el sur andino" (Cooperación Internacional Chile-Francia). ECOS / CONICYT C06H04 "La mort et les pratiques funéraires dans les Andes du Centre-sud de l'époque préhispanique à nos yours" (Cooperación Internacional Chile-Francia). CNRS/CONICYT.
"El sistema de chullpas en la precordillera de Arica. Análisis constructivo, tipología, asociación cultural y distribución espacial" DIPOG UTA. 3706. Asimismo, se agradece el apoyo del Convenio de Desempeño Universidad de Tarapacá-MINEDUC, igualmente se aprovecha la ocasión para agradecer a los evaluadores que contribuyeron a mejorar este artículo.

\section{Referencias Citadas}

Aldunate, C. 2001a. El Inka en Tarapacá y Atacama. En Tras las Huellas del Inka en Chile: 19-44. Museo Chileno de Arte Precolombino.

- - - 2001b. Arquitectura y Poder. En Tras las Huellas del Inka en Chile: 45-51. Museo Chileno de Arte Precolombino.

Aldunate, C., J. Berenguer y V. Castro 1978. La función de las Chullpas en Likán. Actas del VIII Congreso de Arqueología Chilena: 129-174. Sociedad Chilena de Arqueología, Universidad de Chile. Valdivia.

Aldunate, C y V. Castro 1981. Las Chullpas de Toconce y su Relación con el poblamiento Altiplánico en el Loa Superior Período Tardío. Tesis para optar al grado de Licenciado en Filosofía con mención en Prehistoria y Arqueología, Universidad de Chile, Santiago.

Álvarez, B. 1998 [1588]. De las Costumbres y Conversión de los Indios del Perú: Memorial a Felipe II. Ediciones Polifemo, Madrid.

Ayala, P. 1998. Apropiación y transformación de arquitectura altiplánica en la región del Loa Superior: la aldea de Talikuna. Actas del XIV Congreso de Arqueología Chilena, Copiapó, Chile.

Bandelier, A. 1910. The Island of Titicaca and Koati, New York.

Berenguer, J., C. Aldunate y V. Castro 1984. Orientación orográfica de las chullpas en Likán: la importancia de los cerros en la fase Toconce. Simposio Culturas Atacameñas, 44 Congreso Internacional de Americanistas, Manchester. Universidad del Norte, Antofagasta.

Chacama, J. 2007. El sistema chullpas en la precordillera de Arica. Análisis constructivo, tipología, asociación cultural y distribución espacial. Informe final del proyecto 3706, Universidad de Tarapacá.

- - - 2010. Cuatro puntos sobre los gorros de cuatro puntas. Aproximación al rol social de una prenda de vestir precolombina. Memoria para optar al título profesional de Arqueólogo. Universidad de Chile, Santiago.

Cieza de León, P. 1988 [1553]. La Crónica del Perú. Nueva Biblioteca Peruana, Lima.

Cobo, B. 1964 [1653]. Historia del Nuevo Mundo BAE XCII. Altas, Madrid.

D’Orbigny, A. 2002 [1839]. Viaje a la América meridional. IFEA. Lima.

Duchesne, F., 2005. Tumbas de Coporaque. Aproximaciones a concepciones funerarias collaguas. Bulletin de l'Institut Français d'Études Andines 34:379-410.
- - - 2008. L'ajustement Indien. Les Villages du Coropuna au 18 e siècle. Tesis de Doctorado. Paris III, Sorbonne Nouvelle, Paris.

Duday, H., Masset, C. 1987. Anthropologie Physique et Archéologie. Édition du CNRS, Paris.

Duviols, P. 1966. Un procès d'idolâtrie. Arequipa, 1671. En Fenix, Revista de la Biblioteca Nacional 16, Lima.

- - - 1973. Huari y Llaguaz. Agricultores y pastores: un dualismo prehispánico de oposición y complementariedad. Revista del Museo Nacional 39, Lima.

Durston, A. y J. Hidalgo 1999. La presencia andina en los valles de Arica, siglos XVI - XVIII: casos de regeneración colonial de estructuras archipielágicas. Chungara 29:210-249.

Franco, J.M. 1937. Informe sobre el reconocimiento de restos arqueológicos en las cabeceras de Paucartambo. Revista del Museo Nacional VI (2):255-277. Lima.

Gisbert, T. 2001. El Paraíso de los Pájaros Parlantes. La Imagen del Otro en la Cultura Andina. $2^{\text {a }}$ Edición. Editorial Plural, La Paz.

- - - 1996. Los Chullpares del Río Lauca. Academia Nacional de Ciencias de Bolivia, La Paz.

Gutiérrez, N. 1935. Ciudadelas Chulparias de los Wankan. Revista del Museo Nacional VI (1):43-51. Lima.

Heredia, M. 1993. Las torres funerarias de Kullikulli. Pumpunku 2 (5-6):162- 171.

Huaman Poma de Ayala, F. 1980 [1615]. El Primer Nueva Crónica i Buen Gobierno. Siglo Veintiuno. México.

Hidalgo, J. 1999. Relaciones protohistóricas interétnicas entre las poblaciones locales y altiplánicas en Arica. En La Integración Sur Andina Cinco Siglos Después, editado por X. Albó et al., 161-173. Centro de Estudios Bartolomé de Las Casas.

Hidalgo, J. y A. Durston 1998. Reconstitución étnica colonial en la sierra de Arica. El Cacicazgo de Codpa 1650-1780. Actas del IV Congreso Internacional de Etnohistoria, Tomo II:32-75, PUCP, Lima.

Hyslop, J. 1977. Chullpas of the Lupaca zone of the Peruvian High Plateau. Journal of Field Archaeology 4:149-170.

Isbell, W.H. 1997. Mummies and Mortuary Monuments. A Postprocessual Prehistory of Central Andean Social Organization. University of Texas Press, Austin.

Kesseli, R., P. Liuha y M. Rossi 1999. Archaeological and Geographical research of Precolumbian (AD 1200-1532) Grave Towers or Chullpa on the Bolivian High Plateau in the Years 1989-1998. Preliminary report. Dig it all: Papers dedicated to 
Ari Siiriäinen: $335-348$. The Finnish Antiquarian Society, The Archaeological Society of Finland, Helsinki.

Kesseli, R., J.A. Sagárnaga Meneses, A., Korpisaari y J. Bustamante 2003. Informe sobre las investigaciones arqueológicas realizadas en torres funerarias de piedra de Taramaya, Provincia Los Andes, Agosto 2002. Noticias del proyecto arqueológico finlandésboliviano en la Amazona boliviana II: 97-120. Departamento de Arqueología, Universidad de Helsinki.

Kesseli R. y M. Pärssinen 2005. El altiplano boliviano de Pakasa: Identidad étnica y muerte: torres funerarias (chullpas) como símbolo de poder étnico (1250-1600 d.C.). Bulletin de l'Institut Français d'Études Andines 34:379-410.

Las Casas, B. 1967 [1552-1561]. Apologética Historia Sumaria. Editado por E. O'Gorman, UNAM, México.

Latcham, R. 1915. Costumbres Mortuorias de los Indios de Chile y Otras Partes de América. Soc. Imprenta-Litografía "Barcelona", Santiago - Valparaíso.

Lumbreras, L. 1974. La Arqueología como Ciencia Social. Ediciones Históricas. Ed. Nueva Educación, Lima.

Marcoy, P. 2001 [1869]. Viaje a Través de América del Sur, del Océano Pacífico al Océano Atlántico. T.1. IFEA, PUCP. Lima.

Mc Bain, H. 1959. The Adolph Bandelier Archaeological collection from Pelechuco and Charassani, Bolivia. Revista del Instituto de Antropología. Rosario.

Mercado de Peñalosa, P. 1965 [1586]. Relación de la provincia de los Pacajes. En Relaciones Geográficas de Indias-Perú. Editado por Jiménez de la Espada, T.1. BAE CLXXXIII:335-341, Atlas, Madrid.

Muñoz, I., J. Chacama, G. Espinosa y L. Briones 1987. La ocupación prehispánica tardía de Zapahuira y su vinculación a la organización económica y social Inca. Chungara 18:67-89.

Muñoz, I., J. Chacama y M. Santos 1999. Tambos, pukaras y aldeas, evidencias del poblamiento humano prehispánico tardío y de contacto indígena europeo en el extremo norte de Chile. Diálogo Andino 16:123-190.

Murra, J. 1975. El control vertical de un máximo de pisos ecológicos en la economía de las sociedades andinas. En Formaciones Económicas y Políticas del Mundo Andino: 59116. Institutos de Estudios Peruanos.

Nora, P. 1997 [1984]. Les Lieux de Mémoire. Gallimard (Quarto), 3 tomos, Paris.

Nordenskiöld, E. 1953 [1906]. Investigaciones arqueológicas en la región fronteriza del Perú y Bolivia. Biblioteca Paceña, Alcaldía Municipal, La Paz.

Pärssinen, M. 1992. Tawantinsuyu. The Inca State and Its Political Organization. Societas Historica Finlandiae, Helsinki.

- - - 1993. Torres funerarias decoradas en Caquiaviri. Pumpunku 2 (5-6):9-32.

Polo de Ondegardo, J. 1917 [1571]. Religión y Gobierno de los Incas. Carlos Romero. Lima.

Posnansky, A. 1918. Los Chipayas de Caranga. Instituto Tihuanacu de Antropología, Etnografía y Prehistoria. La Paz.

Ramos Gavilán, A. 1976 [1621]. Historia de Nuestra Señora de Copacabana. Academia Boliviana de la Historia. La Paz.
Rivière, G. 1979. Intercambio y Reciprocidad en Carangas. Antropología 1 Añol $N^{o} 1$, Revista del Instituto Nacional de Antropología, pp. 85-113, La Paz.

----1982. Sabaya: Structures Socio-Economique et Réprésentations Symboliques dans Les Carangas. Bolivie. Tesis doctoral de etnología $3^{\text {er }}$ ciclo. Ecole de Hautes Etudes en Sciences Sociales, Paris.

Romero, A. 1999. Ocupación multiétnica en la sierra de Arica: arquitectura, uso del espacio y distribución cerámica en el poblado arqueológico de Huaihuarani. http://www.uta.cl/ masma/azeta/huaihua.

- - - 2000. El pukara de Cayllama. Interpretación y manejo del sitio arqueológico. Informe proyecto FONDART № 49716.

- - - 2002. El pucara de Cayllama, las Chulpas de barro y el control político de la sierra de Arica durante el Período Intermedio Tardío. http://www.uta.cl/masma/azeta/caillama.

- - - 2003. Chullpas de barro, interacción y dinámica política en la precordillera de Arica, durante el período Intermedio Tardío. Textos Antropológicos 14(2): 83-103. La Paz.

Ryden, S. 1947. Archaeological Researches in the Highlands of Bolivia. Eanders Boktryckeri Akiebolag, Götteborg.

Santoro, C., A. Romero y V. Standen 2003. Prehistoric burials types, political interaction and ethnic boundaries in the South Central Andes. En Mummies in a New Millennium, editado por N. Lynnerup, C. Andreasen y J. Berglund, pp. 154-158. Danish Polar Center, Copenhagen.

Sagárnaga Meneses, J.A. 1993. La chullpa de Viacha. Pumpunku 2 (5-6):33-55.

Sever, J. 1993 [1952]. Los chullperíos de Pukara. Pumpunku 2 (5-6):172- 178.

Sobczyk, M. 2001. Arquitectura Funeraria prehispánica en la Región del Nevado Coropuna. Boletín de la Misión Arqueológica Andina, Universidad de Varsovia, Varsovia.

Squier, G. 1974 [1877]. Un viaje por Tierras incaicas. Crónica de una Expedición Arqueológica (1863-1865). Editorial Los Amigos del Libro. La Paz - Cochabamba.

Trimborn, H. 1969. Die Chullpa von Atiquipa. Verhandlungen des XXXVIII internationalen Amerikanistenkongresses: 393405 Munich.

- - - 1993 [1959]. Las chullpas de Sica Sica. Pumapunku 2 (5-6):192-208.

Tschopik, M. 1946. Some notes on the archaeology of the Department of Puno, Perú. Papers of the Peabody Museum of American Archaeology and Ethnology 27(3); Harvard University Press, Cambridge, Massachusetts.

Ulloa de Mogollón, J. 1965 [1586]. Relación de la provincia de los Collaguas para la descripción de las indias que su majestad manda hacer. En Relaciones Geográficas de IndiasPerú. T. 1. Editado por Marco Jiménez de la Espada, BAE CLXXXIII:326-333, Atlas, Madrid.

Vázquez de Espinosa, A. 1969 [1629]. Compendio y Descripción de las Indias Occidentales, BAE CCXXXI, Atlas, Madrid.

Wernke, S.A. 2003. An Archeo-history of Andean Community and Landscape: The Late Prehispanic and Early Colonial Colca Valley, Peru. Tesis de Doctorado: Universidad de Wisconsin, Madison. 


\section{Notas}

1 Ver entre otros: Cieza de León (1983 [1553]), Polo de Ondegardo (1917 [1571]), Mercado de Peñalosa (1965 [1586]), Álvarez (1998 [1588]), Huaman Poma de Ayala (1980 [1615]), Ramos Gavillán, 1976 [1621]. Aquellos cronistas han descrito de manera ilustradora cómo los indígenas de los Andes del Centro-Sur edificaban torres para depositar a sus muertos y hacerles sus ritos. Por ejemplo, Cieza de León escribe a mitad del siglo XVI "La cosa más notable y de ver que hay en este Collao, a mi ver, es las sepulturas de los muertos. [...] y así, por las vegas y llanos cerca de los pueblos estaban las sepulturas destos indios, hechas como pequeñas torres de cuatro esquinas, unas de piedra solo y otras de piedra de tierra, algunas y otras angostas [...]". Cieza, 1988 [1553], cap. C., p. 227.

2 Por ejemplo: D’Orbigny (2002 [1839]), Marcoy (2001 [1869]), Squier (1974 [1877]].

3 Son innumerables los estudios dedicados a las torres funerarias. Citamos solamente los más estimulantes de las últimas décadas: Gisbert (1994), Hyslop (1977), Isbell (1996), Kesseli (1999, 2003), Pärssinen (1993, 2003, 2005).

4 Por ejemplo, Antonio Vázquez de Espinosa releva sepulturas sobreelevadas del tipo chullpa en la provincia de León de Huanuco en los Andes Centrales, y en las de los Canas y en el Collao en el área centro-sur. Vázquez de Espinosa (1969[1629]: § 1362, 1609, 1631),

5 Ver Revista Pumapunku 2, nº 5\&6, 1993.

6 El origen cultural de las chullpas ha sido un tema de debate no resuelto entre arqueólogos y etnohistoriadores. ¿Han sido aquellas estructuras el fruto de una evolución cultural de las costumbres funerarias desde Tiwanaku que se difundieron hacia la periferias, o, más bien, se desarrolló aquel fenómeno primero en las periferias donde se encuentran los más remotos rasgos? A nuestro entender, esta "búsqueda de los orígenes" no tiene mucho sentido. Que esta "costumbre" se haya desarrollado independientemente en varios lugares a partir de "algo" en común, o que haya nacido un día, en algún lugar preciso entre los Andes meridionales y centrales para luego difundirse hacia otras zonas de los Andes, no es un punto que podamos precisar con mayor claridad por la falta de documentación actualmente disponible. Pero como haya sido, no importa mucho dentro del objetivo de este trabajo, lo esencial, a nuestro entender, no es que el uso de las chullpas haya sido transmitido o que haya sido inventado, sino que haya sido recibido y aceptado. Que dentro de una población un uso sea introducido por uno de sus miembros creativo, o que aparezca después de la visita -violenta o no- de un vecino, este uso puede echar raíces solamente si responde a necesidades, si están reunidas condiciones favorables: si el grupo está listo para aceptarlo.

7 A $100 \mathrm{~km}$ al norte del Coporaque localizado en el valle del Colca, o sea en la región de procedencia mítica de los Collaguas, se encuentra un pueblo llamado también Coporaque cerca de la ciudad de Yauri.

8 Ver una descripción completa en Duchesne 2005.

9 Este sector de la Cordillera de los Andes a veces es mencionado en la literatura especializada como Altos de Arica

10 En diversos sitios de la precordillera de Arica se aprecian evidencias de keros empotrados en la cara anterior de los edificios chullpas. En ocasiones es un kero y en otras un par. En la zona del altiplano es posible apreciar la impronta de hasta cinco de estos vasos de madera como en algunas chullpas de la localidad de Sabaya en el altiplano de Bolivia.

11 "De diversas maneras se habían las gentes de la sierra en hacer las sepolturas y en los entierros y ceremonias, porque en algunas provincias dellas hacían para sepulturas unas torre altas. Eran huecas en lo bajo dellas, obra de un estado en alto; lo demás era macizo, que o era lleno de tierra o de piedra y canto labrado, y todas muy blanqueadas. En otras partes las hacían redondas y en otras cuadradas, muy altas y juntas con otras y en el campo". Las Casas 1967 [1552-1561].

12 El tema descriptivo no nos interesa aquí y guiamos el lector hacia la abundante literatura sobre el tema, i.e Chacama 2007, Hylop 1977.

13 "Más generales eran las sepulturas altas edificadas sobre la tierra; en las cuales también hallamos gran variedad, porque cada nación buscaba nueva traza para hacerlas" B. Cobo 1964 [1653]:271

14 La mayoría de los edificios interpretados como chullpas han sido encontrados vacíos de restos humanos, esto debido a las sucesivas destrucciones que los afectaron, ya por parte de los evangelizadores y otros extirpadores, ya por saqueadores. Sin embargo, algunos arqueólogos tuvieron la suerte de encontrar chullpas con su contenido algo preservado si no intacto, contenido que muestra un uso colectivo de las sepulturas. Ver, por ejemplo, Korpissaari et al. 2003, Pärssinen y Kesseli 2005, Duchesne 2005.

15 A propóstio de Chuquibamba, Álvarez hace referencia a un pueblo ubicado en el obisbado de Cuzco. Puede ser el pueblo ubicado hoy en el Departamento del Apurimac, provincia de Cuzco, pero también el ubicado al pie del nevado Coropuna, en el Departamento del Condesuyos de Arequipa, toda la provincia de Arequipa perteneciendo al obispado de Cuzco hasta 1610.

16 En artículo de 2003 Romero relativiza la relación Chullpas curacas Caranga, señalando que durante el Intermedio Tardío en la precordillera de Arica se habría llevado a cabo un relación entre tres grupos culturales: altiplánicos, de valles occidentales y serranos, cuyos esquemas ideológicos no habrían sido lo suficientemente estructurados como instaurar una ideología sobre otra.

17 Pärssinen y Kesseli (2005) llaman la atención sobre el hecho dramático de que las chullpas siguen siendo destruidas, hasta tal punto que, según esos especialistas, desaparecerán de Bolivia dentro de 50 años.

18 Ulloa de Mogollón escribe en 1586 que los Collaguas tenían la costumbre -bien difundida en los Andes del Centro-Sur- de deformar sus cráneos: "Estos Collaguas [...] traían en la cabeza unos que llamaban en su lengua chucos, a manera de sombreros muy altos sin falda ninguna, y para que se pudiesen tener en la cabeza, se la apretaban a los niños recién nacidos se la abusaban y adelgazaban alta y prolongada lo más que podían, para memoria que habían las cabezas de tener la forma alta del volcán de donde salieron " (Ulloa de Mogollón 1965 [1586]:327). Ver Duchesne 2005. 
19 "Gobernábanse conforme a lo quel inga tenía puesto, que era, por sus ayllos e parcialidades nombraba de cada ayllo un cacique, y eran tres ayllos, llamados Collana, Pascana ¿Pallan?, Cayao; cada ayllo destos tenía trescientos indios y un principal a quien obedecían, y estos tres principales obedecían al cacique principal, que era sobre todos. Tenía el cacique principal mando y poder sobre todos los demás principales, los cuales le eran obedientísimos en todo lo que mandaba, así en las cosas de la guerra como en las cosas de justicia y castigo de delitos". Ulloa de Mogollón 1965 [1586]:330.

20 Notamos el mismo fenómeno que en zona Caranga: las chullpas no estudiadas ubicadas al pie sur del cerro Sacasani al este del Tata Sabaya están agrupadas a menudo en 2 o 3 y alineadas. Comunicación personal de Erwan Duffait.

21 Su organización social interna, al igual que en los demás señoríos altiplánicos, habría estado constituida sobre la base de ayllus menores y mayores; grupos corporativos de jefatura dual, agrupados en distintos niveles inclusivos, desde la unidad mínima, hasta la gran estructura política identificada en tiempos coloniales como el señorío Caranga (Rivière1982).

22 En 1671 aparece en un proceso de idolatrías llevado a cabo en Salamanca, pueblo vecino al río Colca, que los Indios siguen honrando a sus antepasados y que cada uno tiene su mochadero propio donde rinde culto a "sus padres". A mitad del siglo 18, los Indios de otro pueblo vecino del Colca, Andagua, siguen cuidando a sus muertos depositados en "cuevas", cada "familia" teniendo la suya manca. Declaraciones sobre la práctica de la hechicería e idolatría por los indios del pueblo de Chichas, 1671. BNL, B1701. Publicado también por Duviols [1966] y Procesos de idolatrías de Andagua, 1752. Archivo del Arzobispado de Arequipa [este documento no tiene catalogación], f.16r.

23 Hace más de un siglo, un "padre" de la arqueología andina, Nordenskiöld (1906), en las riberas noreste del lago Titicaca encontró hasta doscientos difuntos en una misma chullpa. Asimismo, Stig Ryden encontró numerosas chullpas de entierros múltiples en las orillas del mismo lago. La arqueología moderna confirma que la gran mayoría de las chullpas eran sepulcros colectivos y, en nuestro caso, las de Coporaque dan otro ejemplo más (Ryden 1947).

24 La huaca de procedencia de los Collaguata es muy posiblemente la huaca Ancocagua descrita por Cieza de León, uno de los santuarios más importantes de los Andes, ubicada al suroeste de Yauri cerca del pueblo de Coporaque en la provincia de Chumbivilcas (Cieza de León 1988 [1553]: cap. 28).

25 Una revisión de los contextos funerarios de valles bajos muestran un claro aumento de las actividades productivas durante la época de período Intermedio Tardío. La presencia de objetos relacionados con actividades de pesca, caza, producción textil se encuentran presente en una gran cantidad de contextos del periodo Intermedio Tardío, a diferencia del período Medio donde son prácticamente inexistentes (Chacama 2010).

26 El proceso de poblamiento de la precordillera de Arica y la descripción de sitios arqueológicos representativos de este, pueden verse de manera amplia en Muñoz y Chacama 2006.

27 William H. Isbell (1996) apoya con razón el papel importante de los muertos y de su culto en la cohesión social de las comunidades pero arriesga sus interpretaciones hasta ver en las sepulturas sobreelevadas tipo chullpa la prueba visible del surgimiento de un nuevo orden social organizado a partir de unidades de parentesco: los ayllus, cuya unidad viene, entre otras cosas, del reconocimiento de un antepasado común honrado gracias y a través de sepulcros visibles y abiertos (para que los vivos tengan acceso al muerto). Sin embargo, y a pesar de un evidente lazo estrecho entre chullpa, antepasado y ayllu, no se puede ver una relación mecánica y directa entre la aparición de las chullpas y la de la institución ayllu. Sencillamente, como ya lo subrayó Martti Pärssinen, porque existen sociedades (en las regiones de Cuzco o de Chuquisaca por ejemplo) en los Andes que desarrollaron una organización social basada en los ayllus y en el culto a los antepasados sin edificar tumbas sobreelevadas.

28 Según Pierre Nora, "Los lugares de la memoria son ante todo restos, la forma extrema bajo la cual subsiste una conciencia conmemorativa en una historia que la solicita, porque la ignora (...) Los lugares de la memoria nacen y viven del sentimiento de que no hay memoria espontánea de que hay que crear archivos, mantener aniversarios, organizar celebraciones, pronunciar elogios fúnebres, labrar actas, porque esas operaciones no son naturales". Nora, 1997: v.1, p. 29.

29 Frente a la represión religiosa de los siglos XVI y XVII, muchos autores, a continuación de Manuel Marzal (1976, 1983), estiman que la vida religiosa andina se "cristalizó" a fines del siglo XVII y que permaneció el "universo sagrado" autóctono en la clandestinidad y en la esfera privada - la esfera pública siendo firmemente ocupada por el Cristianismo. Ver también Griffiths 1998:311-345.

30 Los muertos siendo enterrados bajo tierra durante el Horizonte Medio, el espacio sagrado visible y marcador se resumía entonces a las huellas dejadas por los dioses (cerros, volcanes, lago, etc...), a los monumentos dedicados a estos mismos y a los Señores Principales (templos, pirámides). 
